\title{
COUGH
}

\section{Utility of signs and symptoms of chronic cough in predicting specific cause in children}

\author{
J M Marchant, I B Masters, S M Taylor, A B Chang

See end of article for authors' affiliations

Correspondence to: Correspondence to: Department of Respiratory Medicine, Royal Children's Hospital, Herston, 4029, Queensland, Australia; Julie_Marchant@health. qld.gov.au

Received 7 December 2005 Accepted 20 April 2006 Published Online First 2 May 2006
Background: Paediatricians rely on cough descriptors to direct them to the level of investigations needed for a child presenting with chronic cough, yet there is a lack of published data to support this approach. A study was undertaken to evaluate (1) whether historical cough pointers can predict which children have a specific cause for their cough and (2) the usefulness of chest radiography and spirometry as standard investigations in children with chronic cough.

Methods: This was a prospective cohort study of children referred to a tertiary hospital with a cough lasting $>3$ weeks between June 2002 and July 2004. All included children completed a detailed history and examination using a standardised data collection sheet and followed a pathway of investigation until a diagnosis was made.

Results: In 100 consecutively recruited children of median age 2.8 years, the best predictor of specific cough observed was a moist cough at the time of consultation with an odds ratio (OR) of 9.34 (95\% Cl 3.49 to 25.03$)$. Chest examination or chest radiographic abnormalities were also predictive with OR 3.60 (95\% Cl 1.31 to 9.90$)$ and $3.16(95 \% \mathrm{Cl} 1.32$ to 7.62$)$, respectively. The most significant historical pointer for predicting a specific cause of the cough was a parental history of moist cough (sensitivity $96 \%$, specificity $26 \%$, positive predictive value $74 \%$ ).

Conclusions: The most useful clinical marker in predicting specific cough is the presence of a daily moist cough. Both chest examination and chest radiographic abnormalities are also useful in predicting whether children have a specific cause of their cough. on the usefulness of clinical history and investigations used would be beneficial.

The aim of this study was to evaluate the value of these recommendations, in particular whether (1) historical cough pointers can predict which children have a specific cause for their cough and (2) the usefulness of chest radiography and spirometry as standard investigations in children with chronic cough. We hypothesised that clinical pointers would be present in children with specific cough and absent in children with non-specific childhood cough, and that chest radiography and spirometry would positively identify those with specific cough.

\section{METHODS}

\section{Patient selection and study protocol}

Children with chronic cough $(>3 \text { weeks) })^{12}{ }^{13}$ of unknown aetiology referred to the paediatric respiratory practice at our university hospital between June 2002 and July 2004 were prospectively enrolled in the study. The children attended an initial visit which included detailed history and examination using a standardised data collection sheet. The history included duration and character of the cough, past history of dyspnoea (exertional or chronic), wheeze, haemoptysis, swallowing problems, failure to thrive, allergies, recurrent respiratory tract infections, smoke exposure, upper airway problems including snoring and family history of atopy and asthma. Examination included complete ear, nose and throat, respiratory and cardiovascular examinations, looking particularly for clubbing, chest deformity, cardiac abnormality, or auscultatory abnormality. Exclusion criteria were infants born premature ( $<37$ weeks gestation), children with known lung disease or other severe underlying disorders such as gross neurodevelopmental delay or cardiac abnormalities.

Written informed consent was obtained and the study was approved by our institution's ethics committee. 


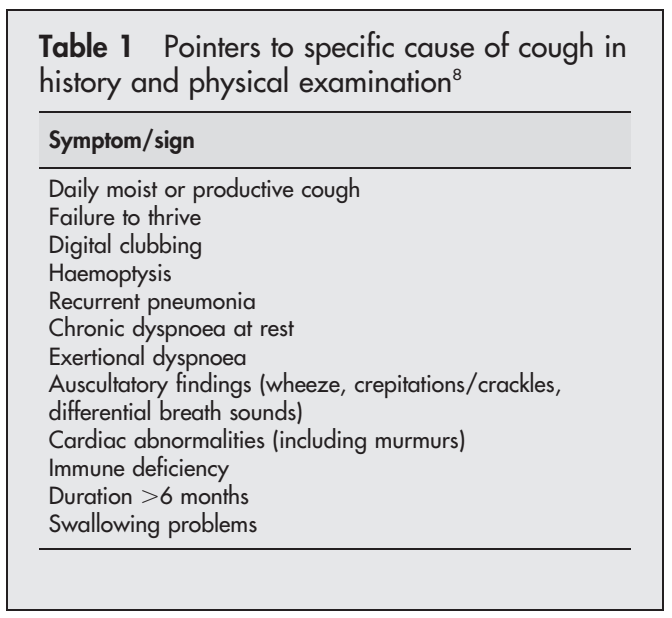

The subjects were investigated and followed using a standardised pathway until diagnosis was made. A high level of investigation was performed to provide objective diagnoses in the cohort. These included chest radiography, spirometry (in children $>6$ years of age), and bronchoscopy and bronchoalveolar lavage in all children to obtain airway cytology, microbiology and inflammatory marker evaluation. High resolution computed tomography of the chest (HRCT) and/or pHmetry were performed in more than half the patients. Laboratory investigations carried out in all patients included sweat chloride test, cystic fibrosis gene mutations (eight most common mutations in Australian population), serum Mycoplasma pneumoniae total antibody and Bordetella pertussis IgA serology, immunoglobulins (IgG, IgM, IgA), total IgE and IgG subclasses. The detailed protocol, investigations used, and number of abnormal results have been published elsewhere. ${ }^{14}$ A validated cough diary ${ }^{15}$ was completed by each patient (or caregiver) throughout the duration of the study to assess response to treatment. Diagnostic categories were reached using standard a priori definitions which included investigation results and response to treatment. Response to treatment was defined as improvement by $>75 \%$ according to cough diary data ${ }^{15}$ or total resolution of the cough. The primary diagnostic outcome was defined as the diagnosis (and subsequent treatment) which resulted in cough resolution.

\section{Clinical definitions}

Non-specific cough was defined as a dry cough with no readily identifiable underlying respiratory disease. ${ }^{79}$ The following diagnoses were classified as non-specific cough in our study: habit cough, gastro-oesophageal reflux disease, upper airway cough syndrome, and children in whom there was natural resolution of the cough. In contrast, specific cough was defined as cough for which an underlying respiratory condition was found and included bronchiectasis, protracted bacterial bronchitis, bronchiolitis obliterans, aspiration lung disease, eosinophilic lung diseases, tuberculosis, B pertussis infection, $M$ pneumoniae infection, and asthma. For the purpose of this study we have defined protracted bacterial bronchitis of childhood as history of chronic moist cough, positive bronchoalveolar lavage culture (growth of $>10^{4}$ colony forming units $/ \mathrm{ml}$ ), and response to antibiotic treatment with resolution of the cough within 2 weeks. Natural resolution was defined as spontaneous resolution of cough without treatment or, if treatments were tried, there was no temporal relationship ( $>2$ weeks) to cough resolution. Protocol clinical definitions are described in table 2. The remaining diagnoses not listed were made by standard clinical practice.

\begin{tabular}{|c|c|}
\hline Diagnosis & Protocol definition \\
\hline $\begin{array}{l}\text { Protracted } \\
\text { bacterial } \\
\text { bronchitis } \\
\text { Natural } \\
\text { resolution }\end{array}$ & $\begin{array}{l}\text { History of chronic moist cough, positive BAL culture } \\
\text { and response to antibiotic treatment with resolution of } \\
\text { the cough within } 2 \text { weeks } \\
\text { Spontaneous resolution of cough without treatment or, } \\
\text { if treatments were tried, there was no temporal } \\
\text { relationship ( } 2 \text { weeks) with cough resolution }\end{array}$ \\
\hline $\begin{array}{l}\text { Asthma-like } \\
\text { conditions }\end{array}$ & $\begin{array}{l}\text { Episodic wheeze and cough with variable airflow } \\
\text { limitation demonstrated by bronchodilator } \\
\text { responsiveness }{ }^{16} \text { and/or response to low dose inhaled } \\
\text { steroids with resolution of cough within first } 2 \text { weeks of } \\
\text { treatment }\end{array}$ \\
\hline Bronchiectasis & $\begin{array}{l}\text { History of chronic cough and the presence of } \\
\text { radiological bronchiectasis on HRCT scan of the chest }\end{array}$ \\
\hline $\begin{array}{l}\text { Aspiration lung } \\
\text { disease }\end{array}$ & $\begin{array}{l}\text { Children with recurrent cough with feeds and patchy } \\
\text { changes on chest radiograph.' The diagnosis was } \\
\text { made on resolution of cough on withdrawing oral } \\
\text { fluids combined with supportive investigations } \\
\text { including modified barium swallow and HRCT changes }\end{array}$ \\
\hline $\begin{array}{l}\text { Gastro- } \\
\text { oesophageal } \\
\text { reflux }\end{array}$ & $\begin{array}{l}\text { Reflux index }(\% \text { time } \mathrm{pH}<4) \text { of } \geqslant 4 \% \text { on pHmetry or } \\
\text { oesophageal biopsy showing reflux oesophagitis' }{ }^{18} \text { and } \\
\text { treatment by standard medical therapy results in } \\
\text { resolution of the cough }\end{array}$ \\
\hline $\begin{array}{l}\text { Eosinophilic lung } \\
\text { disorders }\end{array}$ & $\begin{array}{l}\text { Included eosinophilic bronchitis or hypereosinophilic } \\
\text { syndrome. Eosinophilic bronchitis was defined as an } \\
\text { eosinophil count of }>1 \% \text { of BAL cellular differential or } \\
>2.5 \% \text { of induced sputum cellular differential }{ }^{16}\end{array}$ \\
\hline $\begin{array}{l}\text { Upper airway } \\
\text { cough syndrome }\end{array}$ & $\begin{array}{l}\text { Cough due to upper airway conditions with a history } \\
\text { consistent with diagnosis and response to specific } \\
\text { intranasal treatment within } 2 \text { weeks }\end{array}$ \\
\hline $\begin{array}{l}\text { Bordetella } \\
\text { pertussis and } \\
\text { Mycoplasma } \\
\text { pneumoniae } \\
\text { infections }\end{array}$ & $\begin{array}{l}\text { Diagnosis made if serological evidence of infection (B } \\
\text { pertussis lgA positive, rising total antibody titres to } M \\
\text { pneumoniae) and evidence of these organisms in BAL } \\
\text { using PCR }\end{array}$ \\
\hline
\end{tabular}

Clinicians assessed the character of the cough as "wet" or "dry". As it has been shown that parental reporting of cough quality is reliable, ${ }^{20}$ when the cough was non-assessable by clinicians the parental reporting of cough quality was recorded as "wet" or "dry". An abnormal chest examination was defined as the presence of chest wall deformity or auscultatory findings of crackles, wheeze, or differential air entry. An abnormal chest radiograph was defined by the presence of collapse, consolidation, or hyperinflation. The presence of peribronchial thickening on the chest radiograph was also noted and this finding added to the more significant radiographic findings stated above for further analysis. Chest radiographs were reported by paediatric radiologists working within our tertiary centre who were not involved in any other aspect of this study.

\section{Statistical analyses}

Children were categorised into two diagnostic groups of specific cough and non-specific cough as defined above. Sensitivity, specificity, positive predictive value (PPV), negative predictive value (NPV) and positive likelihood ratio (LR) for the presence of clinical pointers and abnormal investigations in predicting specific cough were calculated. A $\chi^{2}$ test was used for comparison of resolution rates between children with and without wet cough. Odds ratios were used to calculate the value of factors in identifying diagnostic groupings. A two tailed $\mathrm{p}$ value of $<0.05$ was considered significant. SPSS version 12 was used for all statistical calculations.

\section{RESULTS}

\section{Characteristics of patients}

The median age of the 100 consecutive children ( 53 boys) presenting to our institution with chronic cough was 
Table 3 Value of historical pointers in predicting specific cause of cough in children

\begin{tabular}{|c|c|c|c|c|c|}
\hline Historical pointer & Sensitivity (\%) & Specificity (\%) & NPV (\%) & PPV (\%) & LR \\
\hline Moist cough & 96 & 26 & 73 & 74 & 1.29 \\
\hline Duration $>6$ months & 42 & 68 & 34 & 74 & 1.30 \\
\hline Exertional dyspnoea & 38 & 65 & 32 & 70 & 1.06 \\
\hline Chronic dyspnoea† & 7 & 97 & 32 & 83 & 2.25 \\
\hline Recurrent pneumonia* & 7 & 94 & 31 & 71 & 1.12 \\
\hline Haemoptysis & 7 & 97 & 32 & 83 & 2.25 \\
\hline Swallowing problems $\ddagger$ & 25 & 71 & 30 & 65 & 0.85 \\
\hline \multicolumn{6}{|c|}{$\begin{array}{l}\text { NPV, negative predictive value; PPV, positive predictive value; LR, likelihood ratio. } \\
\text { *Defined as } \geqslant 2 \text { episodes of pneumonia in a year or } \geqslant 3 \text { episodes ever. } \\
\text { †Child appears short of breath as defined by parents' awareness of breathing and/or increased respiratory rate } \\
\text { during period of the coughing illness. } \\
\text { tDefined as coughing associated with swallowing liquids or solids one or more time/day throughout coughing } \\
\text { illness. }\end{array}$} \\
\hline
\end{tabular}

2.8 years (interquartile range (IQR) 1.0-6.5). These children were recruited from 106 invited to participate. They had a median duration of cough of 6.0 months (IQR 3.0-12.0) at study recruitment. Specific cough was found in 69 children $(69 \%)$ and non-specific cough in the remaining 31 . The most common diagnosis in the specific cough group was protracted bacterial bronchitis in $45(45 \%)$. Others diagnoses found within this specific cough group included: bronchiectasis $(\mathrm{n}=6)$; asthma-like conditions $(\mathrm{n}=4)$; eosinophilic disorders $(\mathrm{n}=4)$; aspiration disorders $(\mathrm{n}=5) ; M$ pneumoniae infection $(\mathrm{n}=2) ; B$ pertussis infection $(\mathrm{n}=1)$; endobronchial tuberculosis $(\mathrm{n}=1)$; and bronchiolitis obliterans $(\mathrm{n}=1)$. The most common diagnostic group in children with non-specific cough was that of natural resolution in $24(24 \%)$. Others included: habit cough $(\mathrm{n}=1)$; gastro-oesophageal reflux disease $(n=3)$; upper airway cough syndrome $(n=3)$. Of the 29 children who presented with a dry cough, 20 (69\%) resolved naturally. In comparison, in the 71 children with moist cough only $14 \quad(19.7 \%)$ resolved spontaneously $(\mathrm{p}<0.0005)$. The single child with $B$ pertussis infection in our cohort did not have the typical paroxysmal or spasmodic cough characteristic of this diagnosis and presented with an unremarkable dry cough, both on parental history and doctor observations.

\section{Outcomes}

The value of historical pointers in predicting specific cough is shown in table 3. The presence of chronic moist cough was the best detector of specific cough with a sensitivity of $96 \%$, PPV of $74 \%$, and NPV of $73 \%$, although it had a specificity of $26 \%$ only. Chronic dyspnoea and haemoptysis were also strong historical predictors of specific cough with a PPV of $83 \%$, specificity of $97 \%$, and LR of 2.25 for each factor. These pointers were only present in a small number of children so they had a poor sensitivity (7\%) and NPV (32\%). The odds ratio (OR) for the presence of any historical pointers in predicting specific cough was 5.28 (95\% CI 1.23 to 22.73) while the OR for doctor observed moist cough was 9.34 (95\% CI 3.49 to 25.03) (table 4).

Assessment of clinical examination and standard investigations for chronic cough are shown in table 4. In those with an abnormal chest examination the OR was 3.60 (95\% CI 1.31 to 9.90 ) for finding a specific cause of the cough, and in those with an abnormal chest radiograph an OR of $3.16(95 \%$ CI 1.32 to 7.62 ) was found (when peribronchial thickening was considered an abnormal finding).

Table 5 shows the corresponding value of examination and investigation findings in predicting specific cough. A major abnormality on the chest radiograph-defined as the presence of collapse, consolidation or hyperinflation-was a useful marker for specific cough with a specificity of $94 \%$, PPV of $87 \%$, and LR 2.92. An abnormal chest examination was shown to have a specificity of $81 \%$, PPV of $84 \%$, and LR 2.40 for specific cough. The lower prevalence of these findings made their sensitivities poor at $19 \%$ and $46 \%$, respectively.

Thirty two patients aged $>6$ years completed successful spirometric tests and, in this smaller cohort, this equates to an LR of 2.33 for a specific pathology for the cough in children with abnormal spirometry and a specificity of $93 \%$ for spirometry as a diagnostic tool. The infrequency of this finding again made the sensitivity low at $17 \%$ with a PPV of $75 \%$ and NPV of only $46 \%$.

\section{DISCUSSION}

This is the first study which has prospectively evaluated the usefulness of historical and examination markers for predicting a specific cause in children presenting with chronic cough. We have found that the most useful clinical marker in predicting a specific cause of cough is the presence of a daily moist cough. Chest examination and simple

\begin{tabular}{|c|c|c|c|c|}
\hline Historical pointer & $\begin{array}{l}\text { No of patients } \\
\text { with positive } \\
\text { finding }\end{array}$ & $\begin{array}{l}\text { No of patients } \\
\text { with positive } \\
\text { finding and specific } \\
\text { cough }\end{array}$ & Odds ratio & $95 \% \mathrm{Cl}$ \\
\hline Any historical pointer positive & 91 & 66 & $5.28^{*}$ & 1.23 to 22.73 \\
\hline Doctor observed moist cough & 71 & 59 & $9.34^{*}$ & 3.49 to 25.03 \\
\hline Chest examination abnormality & 38 & 32 & $3.60^{*}$ & 1.31 to 9.90 \\
\hline $\begin{array}{l}\text { Any chest radiographic } \\
\text { abnormality (including } \\
\text { peribronchial thickening) }\end{array}$ & 61 & 48 & $3.16^{*}$ & 1.32 to 7.62 \\
\hline Any investigation abnormalt & 17 & 14 & 2.38 & 0.63 to 8.93 \\
\hline
\end{tabular}

*Significant findings.

†Chest radiograph with major abnormality (peribronchial thickening abnormality excluded) or abnormal spirometry. 
Table 5 Value of examination and investigations for predicting a specific cause of cough

\begin{tabular}{|c|c|c|c|c|c|}
\hline Abnormal clinical pointer & Sensitivity (\%) & Specificity (\%) & NPV (\%) & PPV (\%) & LR \\
\hline Chest examination & 46 & 81 & 40 & 84 & 2.40 \\
\hline $\begin{array}{l}\text { Chest radiograph (any } \\
\text { abnormality) }\end{array}$ & 70 & 58 & 46 & 79 & 1.66 \\
\hline $\begin{array}{l}\text { Chest radiograph (major } \\
\text { abnormality) }\end{array}$ & 19 & 94 & 34 & 87 & 2.92 \\
\hline Spirometry* & 17 & 93 & 46 & 75 & 2.33 \\
\hline
\end{tabular}

investigations (chest radiography and spirometry) are useful for predicting if the cough represents a specific underlying lung condition.

There are no studies to our knowledge which have looked at the value of historical and clinical markers in predicting the cause of cough in children. Clinically, physicians rely on these markers to assess which children warrant further investigation and treatment and these pointers are cited as important factors in the assessment of chronic cough in children, ${ }^{8}$ yet their use is based entirely on expert opinion rather then scientific evidence. It has recently been shown that the character of the cough (wet versus dry) is reliably reported by parents ${ }^{20}$ compared with bronchoscopic findings. Our results support this and suggest that parental reporting of wet versus dry cough can help to predict the broad aetiological group within which their child falls.

There are other historical cough descriptors which clinicians use when assessing a child with chronic cough which were not found in our cohort. These include a paraoxysmal or spasmodic cough which is often described with $B$ pertussis infections $(82 \%)$ but can also be found in children infected with Bordetella parapertussis or Chlamydia pneumoniae and in those with respiratory viral illnesses. ${ }^{21} \mathrm{~A}$ barking or brassy cough quality has been recently shown in a prospective assessment of cough quality to have a sensitivity of $57 \%$ and specificity of $81 \%$ for predicting those with tracheomalacia at bronchoscopy. ${ }^{20}$

Non-specific cough is defined as a dry cough with no other underlying identifiable respiratory disease. ${ }^{49}$ Although exceptions have been reported in the literature, ${ }^{22}$ generally these children do not have a serious cause for their $\operatorname{cough}^{2}$ and in many the cough will resolve naturally. ${ }^{14}$ In this study the majority $(70.6 \%)$ with non-specific cough resolved without medical intervention. For the purposes of this study we have included $B$ pertussis and $M$ pneumoniae infection in the specific cough category as they have an underlying respiratory cause for their cough. These diagnoses may have been included in the non-specific cough category as they are part of the differential diagnoses for children with nonspecific cough. ${ }^{9}$ There is an overlap between specific and nonspecific cough groups and these diagnoses illustrate this. ${ }^{8}$ Given the small number of children with these conditions $(\mathrm{n}=1$ and $\mathrm{n}=2$, respectively), describing these diagnoses as non-specific would not have significantly changed our findings.

The importance of making the distinction between nonspecific cough and specific childhood cough with an underlying cardiorespiratory pathology is clear. This study provides evidence that a moist cough is the most sensitive screening tool for assessing whether a child with chronic cough has a specific underlying cause for the cough, although the high prevalence of this finding means it has a lower specificity and there will be false positives among the patients identified. An abnormal chest examination or abnormal chest radiograph should also alert the clinician to the possibility of a specific and potentially serious cause of the cough. The relatively high
PPVs will alert the physician to those children who need to be investigated further, although the relatively low sensitivities of these tools indicate that not all children will be picked up by these pointers.

The limitations of our current study include sample size and patient selection. This is particularly evident when assessing infrequent findings in our cohort such as chronic dyspnoea, recurrent pneumonia, and abnormal spirometry. With a larger sample it is possible that these historical pointers and spirometric findings may have been predictive of specific cough. Selection bias is another limitation of this cohort study but, since almost all eligible children referred to our centre were enrolled in the study, the effect of selection bias should be minimal. During the period of the study the waiting times in our clinic were generally $<3$ weeks. In settings where waiting periods are significantly longer it is possible that more children would undergo spontaneous resolution. However, as children with a wet cough were significantly less likely to undergo spontaneous resolution and more likely to have specific cough, we speculate that our results would still be valid.

Despite this study being based in a tertiary centre, our findings are arguably applicable to primary healthcare facilities. The study has assessed factors within a standard medical history and examination and basic investigations (chest radiography and spirometry) which are routinely used in all healthcare facilities. It highlights the importance of basic investigations - particularly a chest radiograph—when assessing a child with chronic cough, as an abnormal chest radiograph is more likely to indicate underlying specific cardiorespiratory pathology and the need for further follow up. The pointers we have shown to be important in assessing a child with chronic cough should prompt earlier referral to a tertiary centre if diagnosis and successful treatment are not possible in the primary healthcare setting.

This prospective cohort study has assessed the importance of history and examination findings when assessing the cause of chronic cough in a paediatric population. Historical pointers such as chronic dyspnoea and haemoptysis can alert the physician to children with an increased likelihood of specific cough. We have found abnormalities of the chest radiograph and chest examination to be important predicators of the presence of a specific cough. Importantly, we have shown that the presence of a chronic moist cough significantly increased the likelihood of finding a specific cause for the child's cough. We conclude that a history of chronic daily moist cough in children should not be ignored as it increases the likelihood that a specific cause for the cough is present, and this history should prompt early referral to a specialist centre if diagnosis and successful treatment are not available in the primary healthcare setting.

\section{ACKNOWLEDGEMENTS}

The authors thank the children and their parents who so willingly participated in the study and Dr Paul Francis, Dr Claire Wainwright, Professor Alan Isles and Dr Nigel Dore for their assistance with patient recruitment. 


\section{Authors' affiliations}

J M Marchant, I B Masters, S M Taylor, A B Chang, Department of Respiratory Medicine, Royal Children's Hospital, Brisbane, Australia J M Marchant, I B Masters, A B Chang, School of Medicine, Discipline of Paediatrics and Child Health, University of Queensland, Royal Children's Hospital, Brisbane, Australia

$J M M$ is supported by the Royal Children's Hospital Foundation, Brisbane and the TSANZ/Allen and Hanbury's Paediatric Respiratory Medicine Career Development Fellowship. ABC is funded by a Practitioner Fellowship from the National Health and Medical Research Council, Australia.

Conflict of interest: none known.

\section{REFERENCES}

1 Britt H, Miller GC, Knox S, et al. Bettering the evaluation and care of health: a study of general practice activity, Australian Institute of Health and Welfare, 2002.

2 Bush A. Paediatric problems of cough. Pulm Pharmacol Ther 2002; 15:309-15

3 Mello CJ, Irwin RS, Curley FJ. Predictive values of the character, timing, and complications of chronic cough in diagnosing its cause. Arch Intern Med 1996; 156:997-1003.

4 De Jongste JC, Shields MD. Cough. 2: Chronic cough in children, Thorax 2003;58:998-1003.

5 Chang AB, Robertson CF. Cough in children. Med J Aust 2000;172:122-5.

6 Chang $A B$, Asher MI. A review of cough in children. J Asthma 2001;38:299-309.

7 Chang AB. Cough: are children really different to adults? Cough 2005;1:7.

8 Chang $A B$. Causes of cough, assessment and measurement in children. In: Widdicombe JG, Chung F, Boushey H, eds. Cough: mechanisms, causes and therapy. Oxford: Blackwell Science, 2003.
9 Chang $A B$, Powell CV. Non-specific cough in children: diagnosis and treatment. Hosp Med 1998;59:680-4.

10 Chang AB. State of the art: cough, cough receptors, and asthma in children. Pediatr Pulmonol 1999;28:59-70.

11 Chang AB, Phelan PD, Sawyer SM, et al. Airway hyperresponsiveness and cough-receptor sensitivity in children with recurrent cough. Am J Respir Crit Care Med 1997; 155:1935-9.

12 Irwin RS, Curley FJ, French CL. Chronic cough. The spectrum and frequency of causes, key components of the diagnostic evaluation, and outcome of specific therapy. Am Rev Respir Dis 1990;141:640-7.

13 Irwin RS, Boulet LP, Cloutier MM, et al. Managing cough as a defense mechanism and as a symptom. A consensus panel report of the American College of Chest Physicians. Chest 1998;114:81-133S.

14 Marchant JM, Masters IB, Taylor SM, et al. Evaluation and outcome of young children with chronic cough. Chest 2006;129:1132-41.

15 Chang $A B$, Newman RG, Carlin J, et al. Subjective scoring of cough in children: parent-completed vs child-completed diary cards vs an objective method. Eur Respir J 1998;11:462-6.

16 Gibson PG, Fujimura M, Niimi A. Eosinophilic bronchitis: clinical manifestations and implications for treatment. Thorax 2002;57:178-82.

17 Copley SJ, Bush A. Series: Imaging. HRCT of paediatric lung disease. Paediatr Respir Rev 2000;1:141-7.

18 Rudolph CD, Mazur $\amalg$, Liptak GS, et al. Guidelines for evaluation and treatment of gastroesophageal reflux in infants and children: recommendations of the North American Society for Pediatric Gastroenterology and Nutrition. J Pediatr Gastroenterol Nutr 2001;32(Suppl 2):S1-31.

19 Irwin RS, Baumann MH, Bolser DC, et al. Diagnosis and management of cough. Executive summary: ACCP evidence-based clinical practice guidelines, Chest 2006;129:1-23S

20 Chang $A B$, Gaffney JT, Eastburn MM, et al. Cough quality in children: a comparison of subjective vs, bronchoscopic findings. Respir Res 2005:6:3.

21 Marchant J, Morris P, Gaffney J, et al. Antibiotics for prolonged moist cough in children. Cochrane Database Syst Rev 2005;(4):CD004822.

22 Thomson F, Masters IB, Chang AB. Persistent cough in children: overuse of medications. J Paediatr Child Health 2002;38:578-81.

\section{LUNG ALERT}

Inhaled corticosteroid use in young children at high risk of asthma

$\Delta$ Guilbert WT, Morgan WJ, Zeiger RS, et al. Long-term inhaled corticosteroids in preschool children at high risk for asthma. N Engl J Med 2006;354:1985-7

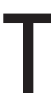
he PEAK (Prevention of Early Asthma in Kids) clinical trial tested the hypothesis that the natural history of wheezing in early life may be altered by the continuous administration of inhaled corticosteroids. This multicentre, double blind, placebo controlled trial randomised 285 preschool children (aged 2-3 years) with a positive asthma predictive index to inhaled fluticasone or masked placebo for 2 years, followed by a 1 year observation period without study medication. The primary outcome was the difference between study groups in the proportion of episode-free days during the observation period.

During the observation year no significant differences were seen between the two groups in the proportion of episode-free days, exacerbation frequency, or lung function. Whilst on treatment, children receiving fluticasone had a greater proportion of episode-free days $(93.2 \% \vee 88.4 \%, p=0.006)$ and a lower rate of exacerbations (57.4 $v 89.4$ events per 100 child/years, $\mathrm{p}<0.001$ ) and the supplementary use of various additional medications (all $\mathrm{p}<0.001)$.

Decreased growth velocity was observed in the inhaled corticosteroid group during the first year. The growth rate was similar during the second year and, although growth accelerated in the corticosteroid group during the observation year, the height difference at the trial end was $0.7 \mathrm{~cm}(\mathrm{p}=0.008)$.

The authors conclude that the natural course of asthma in young children at high risk for subsequent asthma is not modified by 2 years of treatment with inhaled corticosteroid. However, the treatment did reduce the burden of illness. This study shows that inhaled corticosteroid can be used to control active disease but not to prevent asthma in high risk preschool children.

L E R McLure

Clinical Research Fellow, Scottish Pulmonary Vascular Unit, Western Infirmary, Glasgow, UK lindseymclure@yahoo.co.uk 